\title{
Effect of Physical Environment on the Behaviors of Residents with Dementia: A Comparison between a Small-Group Unit and a Traditional Care Unit
}

\author{
Sookyoung Lee ${ }^{1}$, Habib Chaudhury ${ }^{2}$ and Soojin Lee ${ }^{3}$ \\ 1. Department of Environmental Design for the Elderly, Research Center Design \& Health, Stockholm 16966, Sweden \\ 2. Department of Gerontology, Simon Fraser University, Vancouver BC V6B 5K3, Canada \\ 3. Symbiotic Life-Tech Research Center, Yonsei University, Seoul 120-749, Korea
}

\begin{abstract}
This is a comparative study examining the influence of a small-scale dementia unit and a traditional dementia unit on behaviors of the residents. The small-scale unit and the traditional unit were selected through two phases in Vancouver, Canada. Seven residents from each facility completed the study. Physical environmental assessments were performed using two tools: PEAP (professional environmental assessment protocol) and TESS-NH (therapeutic environment screening survey for nursing homes). For the assessment of residents' behaviors, three assessment tools were used: MOSES (multidimensional observation scale for elderly subjects), MDS (minimum data set) and DCM (dementia care mapping). The study found that the residents living in a small-scale environment were more engaged in activities and more likely to respond in understanding their fellow residents. Residents living in a traditional long-term care exhibited fewer signs of social interaction. The findings suggest that a small-scale homelike environment could positively influence people with dementia to be more engaged in social exchanges and activities, and consequently help in reducing their withdrawn behavior.
\end{abstract}

Key words: Dementia, small scale, dementia unit, homelike environment, long-term care.

\section{Introduction}

Dementia is a syndrome that can be caused by numerous progressive disorders that impair memory, thinking, behavior and the ability to perform daily activities. These disorders not only decline a person's health and ability to function, but also have an undesirable impact on quality of life and social relationships. Dementia affects about $6 \%$ of people aged 65 to 74 and as many as 30\%-50\% of people older than 85 year. Currently, 35.6 million people around the world live with dementia, about 750,000 of whom live in Canada $[1,2]$. In the next few decades, as the proportion of the population over age 65 continues to increase and the risk of dementia increases with age,

Corresponding author: Sookyoung Lee, Ph.D., senior researcher, research fields: environmental design for older adults and design for dementia. E-mail: sookyoung23@gmail.com. the incidence of dementia and related disease will be accelerating. In Canada, half the people with dementia live in residential care facilities. According to epidemiological study, $20 \%-40 \%$ of residents in residential care facilities and more than $50 \%$ of nursing home residents have moderate or severe dementia [3]. With this large cohort of people with dementia in institutional care facilities, supportive or responsive physical environment is an important component of the care model because of their limited cognitive and physical functions to be considerably related to their immediate surroundings. The institutional environment exerts a fundamental effect on older adults with dementia, who may benefit from a wide range of environmental interventions to compensate the function [3, 4]. Historically, the role of setting as a therapeutic intervention for people with dementia has been quite limited. Most care facilities are still built on 
the traditional hospital model which understands those settings as an efficient delivery place for medical technology $[5,6]$. As some researchers asserted [7-10], various behavioral disorders including social withdrawal and depression are frequent among residents with dementia living in institution-like facilities. Facilities designed on the institutional model of care deprive individuals of their familiar and meaningful environmental past [11]. After some critical evidences have shown that problematic behaviors were reduced or alleviated in a purpose-built dementia care home [12-16], a growing movement toward transforming into a small-scale and homelike environment with more private rooms has launched worldwide to aim at enhancing residents' quality of life. Beck-Friis [12], who moved six older adults with dementia from institutions to the Baltzargården Group Home in Sweden, found that none of them required diapers and sleeping pills, or psycho-pharmaceuticals, and their aggressive behavior ceased within three years. A recent study of "De Hogeweyk" dementia care home in the Netherlands noted that, by providing a small-scale and homelike environment with considering residents' lifestyle, their challenging behavior and the use of incontinence material and medicine decreased significantly [16]. The Netherlands government encourages its concept and aims at 33\% of all institutional dementia care facilities into small-scale environment until 2015 [17]. In North America, similar concept can be seen in a green house blended architecturally with other homes in its neighborhood. Institutional characteristics such as long corridor, large group and institutional furnishings are antithetical to the green house [18]. Small-scale approach in Japan is currently established as a social service and an effective tool for dementia care [19].

Although studies examining the effect of environmental design on the quality of life of people with dementia are growing, much empirical research is needed for an understanding of the effect of small-scale environment in dementia care settings.
Insight into the impact of the environment on older adults with dementia is essential to enhance their quality of life. The overall goal of this study was to examine the comparative effect of a purpose-built small-scale dementia care unit environment and a traditional residential care environment on the functioning and behaviors among residents with dementia in Vancouver, Canada.

\section{Method}

\subsection{Participating Facilities}

To achieve the purpose of the study, a purpose-built small-scale dementia care unit and a traditional dementia care unit were selected in two phases. In the first phase, 10 dementia care facilities were selected randomly from total 56 residential care facilities in Vancouver Costal Health Authority, British Columbia, Canada. Through site visits, the care facilities were classified as a traditional setting and a small-scale setting based on three distinct physical characteristics, which are mainly mentioned as discriminators, e.g., in Refs. [17, 20, 21]. Three physical characteristics used during this phase were number of residents in a unit ( $>$ 20 residents as a large unit), length of corridor ( $>15 \mathrm{~m}$ as a long corridor) and building layout (double-loaded plan $^{1}$ as a traditional unit). Two dementia care units named "Marine Manor" and "Edgewood Home" were selected for the study - high and low conditions for the environmental characteristics from the three criteria. Marine Manor, selected as a traditional care setting, has 30 residents with dementia, a long corridor $(41.3 \mathrm{~m})$ and double-loaded plan. Edgewood Home, selected as a small-scale care setting, has 12 residents with dementia, a relatively short corridor $(14.4 \mathrm{~m})$ and single-loaded plan.

The study received institutional approval from the Research Ethics Board in Simon Fraser University, the Vancouver Coastal Health Authority and executive

${ }^{1}$ Double-loaded plan refers to corridor or hallways that have resident rooms on its both sides, contrasted with single-loaded plan where rooms are on one side of the corridor. 
staff members in the selected care facilities.

\subsection{Study Subjects}

Residents eligible for inclusion in this study were: aged 65 and older, in early-mid stage of Alzheimer's disease or a related dementia, and able to ambulate with or without an assistive device. To get sufficient observational data, the study excluded residents who were lying in bed or staying in their private rooms during the daytime. Within each facility, a general manager or/and a care director listed eligible residents and contacted their family members by letter or phone to seek consent until seven residents were obtained. In Edgewood Home, there were only three eligible residents residing on the 1 st floor. Four additional residents were attained from the 3rd floor unit having similar design features with the 1st floor unit. Seven residents from each facility completed the study. The residents ranged in age from 73 to 95 years in Edgewood Home and 62 to 88 years in Marine Manor. There were four men and three women from Edgewood Home and three men and four women from Marine Manor.

\subsection{Measurement}

\subsubsection{Physical Environmental Assessment}

Physical environmental assessments at Edgewood Home and Marine Manor were performed on January 30 and February 21, 2012 using two standardized environmental assessment tools: PEAP (professional environmental assessment protocol) [22] and TESS-NH (therapeutic environment screening survey for nursing homes) [23]. Two researchers used PEAP and TESS-NH to assess the facility, ensuring data reliability.

PEAP is composed of eight physical environmental dimensions of a dementia care setting. These eight dimensions include: safety and security, maximize awareness and orientation, support functional ability, facilitation of social contact, provision of privacy, opportunities for personal control, stimulation, and continuity of self. Each aspect was ranked on a scale from 1 (being very poor) to 5 (being excellent).
TESS-NH contains 84 discrete items and one overall item that generally cover six domains with 13 sub-domains. These domains include: (1) privacy/control/autonomy: unit autonomy, access to outdoors and privacy; (2) safety/security/health: exit control, maintenance, cleanliness and safety; (3) stimulation: lighting, visual/tactile stimulation and noise; (4) socialization: space and seating; (5) personalization/familiarity: familiarity and homelikeness; (6) orientation: orientation and cueing. Defining specific physical features were primarily rated on a scale from 0 (distinctly unpleasant attribute) to 3 (more favorable attribute).

\subsubsection{Residents' Behavioral Assessment}

For the assessment of physical functioning, cognitive status and social behaviors of the residents with dementia, three specific assessment tools were utilized from February to April, 2012: (1) MOSES (multidimensional observation scale for elderly subjects) [24]; (2) MDS (minimum data set-version 2.0); (3) DCM (dementia care mapping) [25].

MOSES is a compilation of five behavioral dimensions with 40 items: (1) self-care functioning (e.g., dressing, bathing, grooming, etc.); (2) disoriented behavior (e.g., understanding communication, recognizing staff, awareness of time, etc.); (3) depressed/anxious mood (e.g., sad and depressed, looking worried and anxious, etc.); (4) irritable behavior (e.g., irritability, reactions to frustration, etc.); (5) withdrawn behavior (e.g., preferring solitude, responding to social contacts, etc.). Rating scale was used from 5 (positive to great degree) to 1 (negative to great degree). Care aides in charge of taking care of the selected residents were asked to answer the questions of MOSES.

The RAI-MDS 2.0 (resident assessment instrument minimum data set version 2.0) is a comprehensive, standardized tool to assess residents in long-term care settings. Assessment with this instrument enables detection of residents' strengths, needs and potential risks to inform individualized care planning and 
monitoring. MDS used in the study contains 132 items that cover 13 domains: cognitive patterns, communication patterns, $\mathrm{mood} /$ behavior patterns, psychosocial well-being, physical functioning problems, continence, disease diagnoses, health conditions, oral status, skin condition, activity pursuit patterns and medications. These data were obtained from a registered nurse at each care facility.

DCM, a technique and mapping method devised to systematically observe and document in detail the experience of people with dementia, was conducted as follows: the first author conducted unobtrusive observations of the selected residents continuously for 5 min time frames during daytimes in the primary social areas. During each time frame, BCCs (behavioral category codes) and $\mathrm{ME}$ (mood/engagement) values were recorded for each resident being observed. BCCs represent the type of behaviors or interactions in which residents are engaged, whereas ME values capture each resident's emotional state and engagement levels in relation to their activities [25]. There are 23 Behavioral category $\operatorname{codes}^{2}$ and six corresponding

\footnotetext{
${ }^{2} \mathrm{~A}$. Articulation (interacting with others verbally or otherwise); B. Borderline (being engaged but passively, e.g., watching); C. Cool (being disengaged, withdrawn); D. Doing for self (engaging in self-care, e.g., combing hair, tying shoe lace); E. Expressive (engaging in an expressive or creative activity, e.g., singing, dancing); F. Food (eating or drinking); G. Going back (reminiscence and life review, e.g., looking at photo of family); I. Intellectual (prioritizing the use of intellectual abilities, e.g., completing crosswords or puzzles); J. Joints (engaging in exercise or physical sport); K. Kum \& go (walking, standing or moving independently or in a wheelchair); L. Leisure (engaging in leisure, fun \& recreation); N. Nod (sleeping or dozing); O. Objects (displaying attachment to or relating to inanimate objects such as dolls, toys, handbags); P. Physical (receiving practical, physical or personal care, e.g., being given medication); R. Religion (engaging in a religious activity); S. Sexual expression; T. Timalation (direct engagement of the senses, e.g., touching objects for the purpose of experiencing their texture or smell); U. Unresponded to (attempting to communicate but not receiving a response); V. Vocational (engaging in work or work-like activities, e.g., watering plants, washing dishes); W. Withstanding (repetitive self-stimulation of a sustained nature, e.g., rocking, rubbing); X. X-cretion (episodes related to urinary excretion or bowel movement); Y. Yourself (engagement in interaction in the absence of any observable other); Z. Zero option (fits none of existing categories).
}

ME values ${ }^{3}$. ME values were coded in the context of the BCCs that they accompanied (i.e., $\mathrm{A} /+1$ or $\mathrm{B} /-1$ ). To get a reliable data, each resident was observed at least over $2 \mathrm{~h}$. Observing time was total $18 \mathrm{~h}$ at Edgewood Home ( $9 \mathrm{~h}$ each on the $1 \mathrm{st}$ and 3rd floor) and $12 \mathrm{~h}$ at Marine Manor.

\subsection{Statistical Analysis}

The data were coded and analyzed using the Excel (2010 version) and SPSS (Statistic Package for the Social Sciences) for Windows, version 21.0 software. The main analysis of the data consisted of descriptive statistics and $t$-test. Mean comparisons between the two groups from Edgewood Home and Marine Manor were performed using $t$-test with a level of significance of less than 0.05 .

\section{Results}

\subsection{Characteristics of the Residents and the Dementia Care Unit}

Table 1 shows the residents' and care unit's general characteristics. The residents ranged in age from 73 to 95 years in Edgewood Home (mean $=81.9$ years, $S D$ (standard deviation) $=7.4)$ and 62 to 88 years in Marine Manor $($ mean $=79.3$ years, $S D=8.8)$. There were were men $(57.1 \%)$, three women $(42.9 \%)$ from Edgewood Home and three men (42.9\%), four women (57.1\%) from Marine Manor. Three residents of Edgewood Home were married (42.9\%) and two of Marine Manor married (28.6\%). The means of stay length were 29.1 months $(S D=26.9)$ and 26.4 months $(S D=16.6)$ with a range of 6 to 73 months and 8 to 60 months, respectively. ADL (activities of daily living) of residents in two facilities ranged from 25-94 (mean $=61.4, S D=31.4)$ and $17-98($ mean $=57.6, S D=31.0)$,

\footnotetext{
${ }^{3} \mathrm{Mood} /$ Engagement values: +5 (exceptionally positive mood or engagement); +3 (considerable signs of positive mood and engagement, concentrating but distractible and/or happy and relaxed) +1 (alert and focused on surroundings with no signs of positive or negative mood); -1 (small signs of negative mood and/or disengaged and withdrawn); -3 (considerable signs of negative mood, anxiety, distress or anger); -5 (extremes of negative mood, rage, grief or despair).
} 
Table 1 General characteristics of the residents and the dementia care unit $(N=14)$.

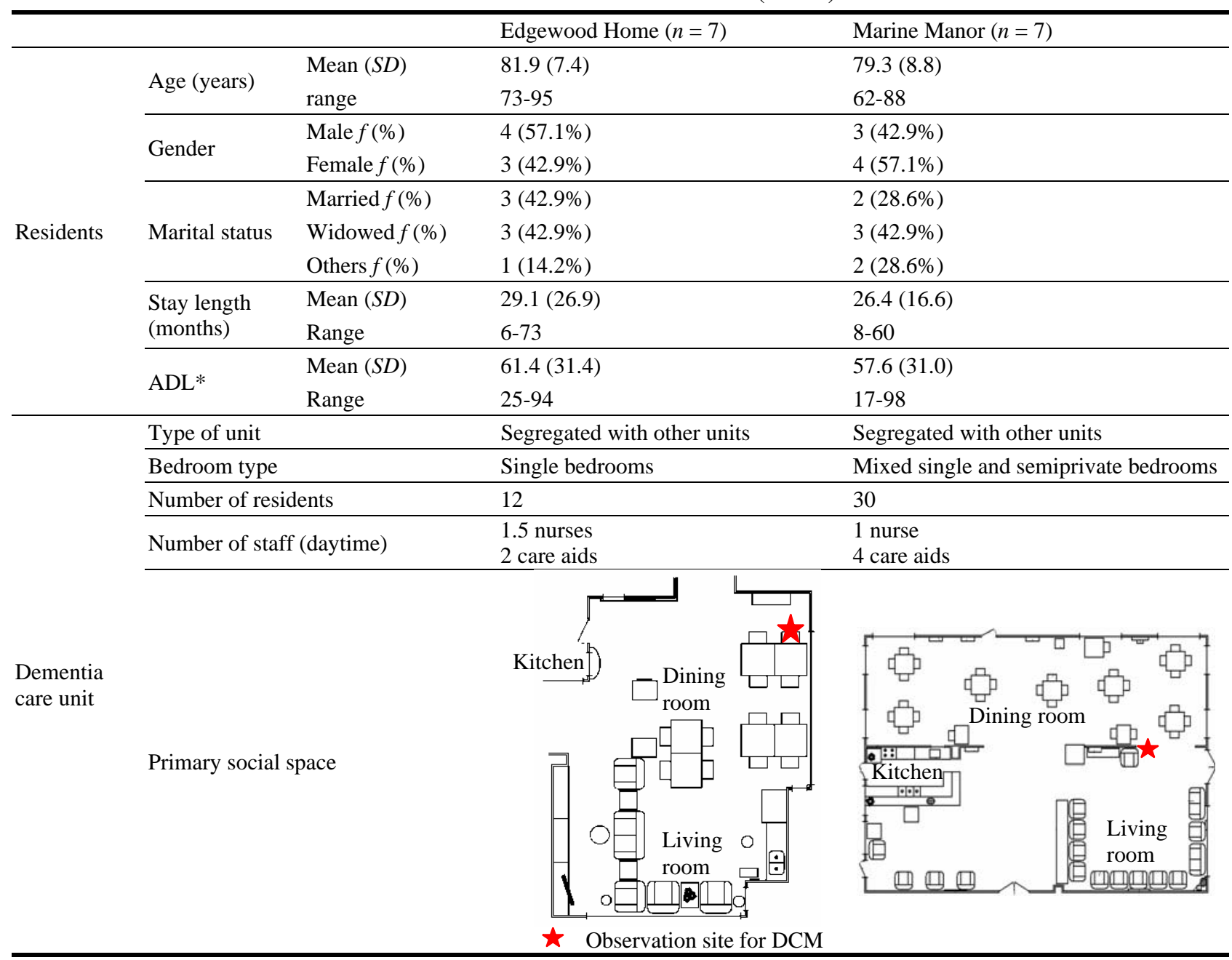

* means activity of daily living: rating from 0 to 100 . The higher the score, the more independent it is.

respectively. The residents in Edgewood Manor were slightly more independent. Generally, the selected residents for the study did not differ between two groups in age, gender, length of stay and ADL.

The two care units were segregated from other sections of the care facility and doors that exit the unit were unlocked by using a keypad. There were all single bedrooms in Edgewood Home, while there were seven single rooms and 11 semiprivate rooms in Marine Manor. The number of residents in the two units was 12 and 30 older adults, respectively. The number of staff working in the daytime was 1.5 nurses and 2 care aides in Edgewood Home and 1 nurse and 4 care aides in Marine Manor. Staff (including nurse) to resident ratio is $1: 3.4$ and 1:6 in each unit and the ratio (excluding nurse) is 1:6 and 1:7.5, respectively.

\subsection{Results of Statistical Analysis}

\subsubsection{Physical Environmental Assessment}

The distribution and tests of statistical significance on the physical environmental assessment of Edgewood Home and Marine Manor are shown in Table 2. Regarding the TESS-NH data, there were significant differences in the stimulation $\left(t_{(38)}=2.19\right.$, $p<0.05)$ and personalization/familiarity/homelikeness $\left(t_{(8)}=4.43, p<0.01\right)$, while the domains of privacy/control/autonomy, safety/security/health, socialization, and orientation revealed no significant differences between the care units. The results indicate that Edgewood Home provided more supportive physical 
Table 2 Means and results of $t$-test analysis on physical environmental assessment.

\begin{tabular}{|c|c|c|c|c|c|}
\hline & & & $\begin{array}{l}\text { Edgewood Home } \\
\text { Mean }(S D)\end{array}$ & $\begin{array}{l}\text { Marine Manor } \\
\text { Mean }(S D)\end{array}$ & $\begin{array}{l}\text { t-value } \\
\text { (two-tailed) (df) }\end{array}$ \\
\hline \multirow{16}{*}{$\begin{array}{l}\text { TESS-NH } \\
\text { (therapeutic } \\
\text { environment } \\
\text { screening } \\
\text { survey for } \\
\text { nursing } \\
\text { homes) }\end{array}$} & \multirow{4}{*}{$\begin{array}{l}\text { Privacy/control/ } \\
\text { autonomy }\end{array}$} & Unit autonomy & $1.33(1.22)$ & $1.22(1.20)$ & \multirow{4}{*}{ N.S. } \\
\hline & & Outdoor access & $2.33(0.58)$ & $1.67(1.15)$ & \\
\hline & & Privacy & 9.00 (n/a) & 1.00 (n/a) & \\
\hline & & Sub-mean $(S D)$ & $2.15(2.34)$ & $1.31(1.11)$ & \\
\hline & \multirow{5}{*}{$\begin{array}{l}\text { Safety/security/ } \\
\text { health }\end{array}$} & Exit control & $1.13(1.25)$ & $1.38(1.92)$ & \multirow{5}{*}{ N.S. } \\
\hline & & Maintenance & $2.00(0.00)$ & $1.00(0.00)$ & \\
\hline & & Cleanliness & $2.00(0.00)$ & $1.67(0.52)$ & \\
\hline & & Safety & $1.83(0.41)$ & $1.83(0.41)$ & \\
\hline & & Sub-mean (SD) & $1.67(0.82)$ & $1.50(1.14)$ & \\
\hline & \multirow{4}{*}{ Stimulation } & Lighting & $1.22(0.44)$ & $0.67(0.50)$ & \multirow{4}{*}{$2.19 *(38)$} \\
\hline & & Visual/ tactile & $2.25(0.96)$ & $1.25(1.50)$ & \\
\hline & & Noise & $1.43(0.53)$ & $1.14(0.90)$ & \\
\hline & & Sub-mean (SD) & $1.50(0.69)$ & $0.95(0.89)$ & \\
\hline & Socialization & Space/seating & $0.90(0.88)$ & $0.50(0.97)$ & N.S. \\
\hline & $\begin{array}{l}\text { Personalization/ } \\
\text { familiarity }\end{array}$ & familiarity/homelikeness & $1.40(1.14)$ & $0.20(0.45)$ & $4.43^{* *}(8)$ \\
\hline & Orientation & Orientation/cueing & $0.54(0.52)$ & $0.38(0.51)$ & N.S. \\
\hline \multirow{10}{*}{$\begin{array}{l}\text { PEAP } \\
\text { (professional } \\
\text { environmental } \\
\text { assessment } \\
\text { protocol) }\end{array}$} & \multirow{2}{*}{\multicolumn{2}{|c|}{ Safety }} & Score & Score & \multirow{10}{*}{$4.06 * * *(14)$} \\
\hline & & & 3.5 & 3.0 & \\
\hline & \multicolumn{2}{|l|}{ Orientation } & 3.0 & 2.0 & \\
\hline & \multicolumn{2}{|l|}{ Support } & 3.0 & 2.5 & \\
\hline & \multicolumn{2}{|l|}{ Social contact } & 3.5 & 2.5 & \\
\hline & \multicolumn{2}{|l|}{ Privacy } & 2.8 & 2.5 & \\
\hline & \multirow{2}{*}{\multicolumn{2}{|c|}{$\begin{array}{l}\text { Personal control } \\
\text { Stimulation }\end{array}$}} & 2.8 & 2.5 & \\
\hline & & & 3.0 & 1.5 & \\
\hline & \multirow{2}{*}{\multicolumn{2}{|c|}{ Continuity of the self }} & 3.5 & 1.5 & \\
\hline & & Mean $(S D)$ & $3.14(0.31)$ & $2.26(0.53)$ & \\
\hline
\end{tabular}

df means degrees of freedom; * means $p<0.05$; ** means $p<0.01$; *** means $p<0.001$; N.S. means not significant; n/a means not applicable.

environmental features in quality of lighting, visual/tactile/acoustic stimuli and a more homelike setting to the residents with dementia as compared to the physical environment of Marine Manor. Global rating on two care units based on TESS-NH was 7.0 and 3.5, respectively.

For PEAP assessment, there was a significant difference between the two care units $\left(t_{(14)}=4.06, p<\right.$ 0.001). Edgewood Home had the higher mean score on PEAP than the one in Marine Manor $($ mean $/(S D)=$ $3.14 /(0.31), 2.26 /(0.53)$, respectively). Of the scores for each domain, continuity of the self (mean $=3.5$, 1.5 , respectively) and stimulation (mean $=3.0,1.5$, respectively) score was found to be the biggest difference between the two care units. The domains of privacy and personal control were slightly higher score in Edgewood Home. This is consistent with the result of TESS-NH.

Generally, the physical environmental assessment demonstrated that Edgewood Home had a more responsive environmental setting for the residents with dementia, especially in providing positive stimuli.

3.2.2 Participating Residents' Behavioral Assessment

The distribution and tests of statistical significance on the residents' diverse behavioral dimensions are shown in Table 3. No statistically significant differences were found in MOSES between the residents at the two care units. Overall, the self-care functioning and the disoriented behavior showed lower mean scores in both of two groups. This means that the residents were more likely to be dependent and less recognized people, place, time or recent event. 
Table 3 Means and results of $t$-test analysis on residents' behavior dimensions $(N=14)$.

\begin{tabular}{lllll}
\hline & & $\begin{array}{l}\text { Edgewood Home } \\
\text { Mean }(S D)\end{array}$ & $\begin{array}{l}\text { Marine Manor } \\
\text { Mean }(S D)\end{array}$ & t-value (two-tailed) (df) \\
\hline Multi-dimensional & Self-care functioning & $19.3(5.5)$ & $20.4(6.2)$ & N.S. \\
observation scale & Disoriented behavior & $20.6(6.3)$ & $18.9(7.4)$ & N.S. \\
for elderly & Depressed/anxious mood & $27.1(5.1)$ & $28.4(6.3)$ & N.S. \\
subjects & Irritable behavior & $28.3(7.4)$ & $28.9(4.1)$ & N.S. \\
& Withdrawn behavior & $22.6(6.9)$ & $19.6(4.4)$ & N.S. \\
\hline & Cognitive patterns & $2.06(0.84)$ & $2.12(0.83)$ & N.S. \\
& Communication patterns & $2.95(0.80)$ & $2.52(0.81)$ & N.S. \\
MDS & Mood patterns & $3.22(1.10)$ & $3.19(1.04)$ & N.S. \\
(minimum & Involvement & $2.29(1.25)$ & $2.00(0.82)$ & N.S. \\
data & Physical functioning & $3.50(1.46)$ & $3.64(1.47)$ & N.S. \\
set) & Continence & $2.33(1.11)$ & $2.39(1.17)$ & N.S. \\
& Disease diagnoses & $2.67(0.53)$ & $2.67(0.57)$ & N.S. \\
& Health conditions & $2.13(0.66)$ & $2.19(0.67)$ & N.S. \\
& Oral/nutrition status & $1.95(0.22)$ & $1.87(0.34)$ & N.S. \\
& Skin condition & $1.66(0.48)$ & $1.63(0.49)$ & N.S. \\
& Activity pursuit patterns & $3.00(0.68)$ & $2.36(0.63)$ & $2.47^{*}(12)$ \\
\hline
\end{tabular}

* means $p<.05$; N.S. means not significant.

Whereas the depressed mood and the irritable behavior showed higher mean scores in both groups, that is, more likely to be less depressed or worried. According to the withdrawn behavior, the residents in Edgewood Home showed slightly higher score than the residents at Marine Manor. This means that the residents at Edgewood Home demonstrated slightly more interest in people, events, activities and social relationship, while the residents at Marine Manor showed withdrawal and apathy regarding people and outside event.

Relative to MDS, there was a statistically significant difference in the activity pursuit patterns $\left(t_{(12)}=2.47, p<0.05\right)$, which showed that the residents at Edgewood Home are more actively engaged in activities than the residents at Marine Manor. No statistically significant difference was found in the communication patterns, but there was a slight gap of means among the two groups. There were also no significant differences in the cognitive patterns, the physical functioning or the health conditions among the two groups.

The distribution of the behavior category profiles for the residents in the two care units was shown in Table 4. During the observation time, the most frequently observed behaviors in the two groups were the articulation $(22.2 \%, 23.7 \%$, respectively), the borderline $(22.0 \%, 23.2 \%$, respectively), the food $(18.5 \%, 18.4 \%$, respectively) and the nod $(11.5 \%$, $11.3 \%$, respectively). The residents, that is, spent three quarters of daily time doing articulation, borderline, food and dozing. There was a distinguishing difference in the cool-being disengaged or withdrawn-accounting for $1.0 \%$ among the residents in Edgewood Home and 13.6\% among the residents in Marine Manor.

According to these data, the residents in Marine Manor exhibited less signs of interaction or engagement with anything or anyone around them compared with residents at Edgewood Home. This result is consistent with the outcome of the withdrawn behavior in MOSES, showing withdrawal and apathy toward people and events. Other differences were shown in the behaviors of come and go $(8.3 \%, 3.7 \%$, respectively) and leisure $(3.9 \%, 1.1 \%$, respectively) categories. It suggests that the residents in Edgewood Home were more likely to walk around the public space and engage in a recreational activity compared to the residents in Marine Manor.

In terms of the ME values associated with these 
Table 4 Distribution of dementia care mapping data $(N=14)$.

\begin{tabular}{|c|c|c|c|c|c|}
\hline & & \multicolumn{2}{|c|}{ Edgewood Home } & \multicolumn{2}{|c|}{ Marine Manor } \\
\hline & & $\bar{f}$ & $\%$ & $\bar{f}$ & $\%$ \\
\hline \multirow{18}{*}{$\begin{array}{l}\text { Behavior } \\
\text { category } \\
\text { code }\end{array}$} & A. Articulation (interacting with others) & 91 & 22.2 & 84 & 23.7 \\
\hline & B. Borderline (passively watching) & 90 & 22.0 & 82 & 23.2 \\
\hline & C. Cool (withdrawn) & 4 & 1.0 & 48 & 13.6 \\
\hline & D. Doing for self (self care) & 4 & 1.0 & 1 & 0.3 \\
\hline & E. Expressive (creative activities) & 7 & 1.7 & 0 & 0.0 \\
\hline & F. Food (eating/drinking) & 76 & 18.5 & 65 & 18.4 \\
\hline & K. Come and go (walking, standing) & 34 & 8.3 & 13 & 3.7 \\
\hline & L. Leisure (recreational activities) & 16 & 3.9 & 4 & 1.1 \\
\hline & N. Nod (sleeping, dozing) & 47 & 11.5 & 40 & 11.3 \\
\hline & O. Objects (displaying attachment) & 8 & 2.0 & 1 & 0.3 \\
\hline & P. Physical (receiving personal care) & 11 & 2.7 & 3 & 0.8 \\
\hline & T. Timalation (engagement of senses) & 3 & 0.7 & 0 & 0.0 \\
\hline & U. Unresponded (without receiving a response) & 1 & 0.2 & 0 & 0.0 \\
\hline & V. Vocational (work-like activity) & 5 & 1.2 & 1 & 0.3 \\
\hline & W. Withstanding (repetitive self-stimulation) & 9 & 2.2 & 12 & 3.4 \\
\hline & X. Excretion (excretion) & 1 & 0.2 & 0 & 0.0 \\
\hline & Y. Yourself (interaction in absence of other) & 3 & 0.7 & 0 & 0.0 \\
\hline & Total & 410 & 100.0 & 354 & 100.0 \\
\hline \multirow{7}{*}{$\begin{array}{l}\text { Mood and } \\
\text { engagement } \\
\text { value }\end{array}$} & +5 (very happy/very absorbed) & 8 & 2.2 & 2 & 0.6 \\
\hline & +3 (content, happy/concentrating but distractible) & 70 & 19.3 & 59 & 17.9 \\
\hline & +1 (neutral/intermittent engagement) & 267 & 73.5 & 199 & 60.5 \\
\hline & -1 (small signs of negative mood/withdrawal) & 16 & 4.4 & 65 & 19.8 \\
\hline & -3 (considerable signs of negative mood) & 2 & 0.6 & 3 & 0.9 \\
\hline & -5 (very distressed) & 0 & 0.0 & 1 & 0.3 \\
\hline & Total (mean) & $363(1.17)$ & 100.0 & $329(0.87)$ & 100.0 \\
\hline
\end{tabular}

behavior category, the residents in Edgewood Home had a higher score on the mean (1.17) than the mean (0.87) in Marine Manor. The distribution of positive values $(\geq+1)$ was revealed $95 \%$ and $79 \%$, respectively, and the negative value $(\leq-1)$ was revealed $5.0 \%$ and $21 \%$ in each unit. These results indicate that the residents in Edgewood Home appeared to be considerably more focused on their surroundings and positive in their moods during the observation compared with the residents at Marine Manor.

\section{Discussion}

This study explored the association of physical environmental characteristics and the behavior and functioning of people with dementia in two dementia care facilities. In particular, it comparatively observed the influence of a small-scale dementia care unit and a traditional dementia care unit on the behaviors of selected residents. To assess the diversity of the domains of behaviors, this study utilized multiple instruments: MOSES for assessing the residents' functional and social behaviors, MDS collected as per regulation and DCM for evaluating the quality of care practices.

Edgewood Home, selected as a small-group care unit, was assessed as more homelike, personalized and positively stimulating atmosphere than Marine Manor selected as a traditional care unit. The participating residents in the two care environments had comparable functional profiles. Results of the study indicate that the residents living in the traditional environment exhibited few signs of interaction/engagement with anyone or anything around them. This finding implies that the residents have the potential of increased withdrawn and apathetic behaviors as the physical environmental features are lacking to meet their cognitive and emotional needs. In contrast, the residents living in the small-scale environment demonstrated to be more 
actively engaged or interested in planned activities provided by the care facility. They were also more likely to respond in understanding fellow residents even though they had a similar level of cognitive status and physical health compared to the other group. Findings support that a small-scale, homelike setting may provide more opportunities for meaningful social interaction and activities throughout familiar surroundings. This finding implies that the familiarity of the homelike small-scale environment in the purpose-built care unit could help reduce withdrawn and apathetic behaviors among the residents. The context of a familiar home environment, especially homelike ambience, delivers a therapeutic process and may make life in a facility a more cognitively comprehensible for older adults with dementia [11]. Zeisel et al. [10] found similar finding in their study showing that residents in facilities with more personalization generally demonstrated less anxiety and aggression. This finding is also consistent with the studies by Lee and Dilani [7], Amerongen-Heijer [16] and Cioffi et al. [26], and a homelike environmental setting played a role to influence positive behaviors in residents with dementia. Having familiar homelike atmosphere may also reinforce frontline staff members to provide quality care, which is related to enhance residents' well-being.

The study also showed that the residents spend most of the daytime passively watching, eating or drinking, dozing and, occasionally, interacting with others. In the small-scale setting which offered more homelike and positive stimulation, the residents displayed increased positive mood and engagements. Meanwhile, the residents in the traditional care unit demonstrated more passive and withdrawn status. Negative behaviors like passively watching, dozing and being cool may decrease well-being and could result from lack of positive stimulation. This finding may support the assertion of other studies [27-29] that too little stimulus from the surrounding environment is associated with a decline in function and cognition and an increase in challenging behavioral symptoms. According to the progressively lowered stress threshold model [24], negative outcomes were associated with excessively low levels of environmental stimulation as well as excessively high levels of stimulation.

The small sample size of this study limits generalization of the findings. The study also did not collect qualitative data to make an in-depth evaluation of the behaviors of the residents with dementia. To enhance generalizability of findings in the future, it would be important to include diverse functional and disease stages of participants. Nevertheless, the overall results of the study provide evidence that a small-scale residential care facility can serve as a therapeutic environmental component for residents with dementia and a traditional care facility tends to influence socially withdrawn behaviors in the residents. The findings suggest that it may be helpful for a traditional long-term care facility to organize small groups within the larger whole and create more personalized and homelike atmospheres.

\section{Conclusions}

This study examined the influence of physical environmental characteristics on the behavior and functioning of people with dementia in dementia care facilities. Based on the findings, it can be concluded:

- The homelike small-scale environment in a dementia care unit could help enhance social interaction and mitigate withdrawn and apathetic behaviors among the residents;

- It is essential to consider a balance between deprived and stressful stimulation in a dementia care setting;

- To create the maximum effect of a positive physical setting on residents with dementia, the social and organizational components must be considered simultaneously. Future studies need to closely examine the interrelation among the physical environment, social (e.g., relationships between 
residents and staff) and organizational (e.g., facility policies, care philosophy and staffing structure) context. It must be recognized that a therapeutic physical environment for people with dementia exists as an integral part of a larger and complex system and needs to be congruous with the social and organizational dimensions of facility.

\section{Acknowledgments}

This research was supported by Basic Science Research Program through the NRF (National Research Foundation of Korea) funded by the Ministry of Education, Science and Technology (NRF-2011-0009776).

\section{References}

[1] World Health Organization \& Alzheimer's Disease International, Dementia: A Public Health Priority [Online], http://www.who.int/mental_health/publications/dementia _report_2012/ en/ (accessed Jan. 1, 2012).

[2] Canadian Institutes of Health Research, Information about Alzheimer's and Related Dementias [Online], http://www.cihr-irsc.gc.ca/e/45554.html (accessed Dec. 5, 2013).

[3] J. Garre-Olmo, S. Lopez-Pousa, A. Turon-Estrada, D. Juvinya, D. Ballester, J. Vilalta-Franch, Environmental determinants of quality of life in nursing home residents with severe dementia, Journal of American Geriatrics Society 60 (7) (2012) 1230-1236.

[4] J. van Hoof, H.M. Kort, H. van Waarde, M. Blom, Environmental interventions and the design of homes for older adults with dementia: An overview, American Journal of Alzheimer's Disease \& Other Dementias 25 (3) (2010) 202-232.

[5] C.A. Leibrock, Design Details for Health: Making the Most of Interior Design's Health Potential, John Wiley \& Sons, INC, USA, 2000.

[6] R.S. Ulrich, Effects of healthcare environmental design on medical outcomes, in: A. Dilani (Ed.), Design \& Health, Elanders Svenskt Tryck AB, Sweden, 2001, pp. 49-59.

[7] S.Y. Lee, A. Dilani, Environmental design features and behavioral health for the elderly with dementia, Journal of Asia Interior Design Institutions Association 11 (2011) 69-80.

[8] D. Skea, J. Lindesay, An evaluation of two models of long-term residential care for elderly people with dementia, International Journal of Geriatric Psychiatry 11 (3) (1996) 233-241.
[9] R.B. Wetzels, S.U. Zuidema, J.F. Jonghe, F.R. Verhey, R.T. Koopmans, Determinants of quality of life in nursing home residents with dementia, Dementia \& Geriatric Cognitive Disorders 29 (3) (2010) 189-197.

[10] J. Zeisel, N.M. Silverstein, J. Hyde, S. Levkoff, P. Lawton, W. Holmes, Environmental correlates to behavioral health outcomes in Alzheimer's special care units, The Gerontologist 43 (5) (2003) 697-711.

[11] H. Chaudhury, Quality of life and place-therapy, in: R.J. Scheidt, P.G. Windley (Eds.), Physical Environments and Aging, The Haworth Press, New York, 2003, pp. 85-103.

[12] B. Beck-Friis, At Home at Baltzargården: Caring for the Geriatric Senile in a Small Scale Group Environment, Libris, Sweden, 1988.

[13] H. Chaudhury, L. Hung, M. Badger, The role of physical environment in supporting person-centered dining in long-term care: A review of the literature, American Journal of Alzheimer's Disease \& Other Dementias 28 (5) (2013) 491-500.

[14] L. Husberg, L. Ovesen, Gammal och Fri (Old and Free), Ängsblomman, Sweden, 2007. (in Swedish)

[15] Socialstyrelsen, Good Housing for Older People and People with Disabilities, LTAB Linköpings Tryckeri AB, Sweden, 2000.

[16] Y.E. van Amerongen-Heijer, A creative pioneering neighboring model for demented elderly: "De Hogeweyky" normal living for people with severe dementia, in: The 20th IAGG (International Association of Gerontology \& Geriatrics) World Congress of Gerontology \& Geriatrics, Seoul, Korea, 2013, pp. 23-27.

[17] H. Verbeek, Redesigning dementia care: An evaluation of small-scale, homelike care environments, Dr. Thesis, School for Public Health \& Primary Care, Maastricht University, 2011.

[18] J. Rabig, W. Thomas, R.A. Kane, L.J. Cutler, S. McAlilly, Radical redesign of nursing homes: Applying the green house concept in Tupelo, Mississippi, Gerontologist 46 (4) (2006) 533-539.

[19] U. Yuka, Group Homes in Japan: Approaches to Dementia Care, ProQuest LLC, USA, 2008.

[20] M.P. Calkins, Evidence-based long term care design, Neuro Rehabilitation 25 (2009) 145-154.

[21] P.D. Sloan, S. Zimmerman, F. Walsh, The physical environment, in: S. Zimmerman, P.D. Sloane, F.K. Eckert (Eds.), Assisted Living: Needs, Practices, and Policies in Residential Care for the Elderly, The Johns Hopkins University Press, USA, 2001, pp. 173-197.

[22] G. Weisman, M.P. Lawton, P.S. Sloane, M. Calkins, L. Norris-Baker, The Professional Environmental Assessment Protocol, School of Architecture, University of Wisconsin at Milwaukee, 1996.

[23] P.D. Sloane, M. Mitchell, G. Weisman, S. Zimmerman, K. 


\section{A Comparison between a Small-Group Unit and a Traditional Care Unit}

Foley, M. Lynn, et al., The therapeutic environment screening survey for nursing homes (TESS-NH): An observational instrument for assessing the physical environment of institutional settings for persons with dementia, Journal of Gerontology: Social Sciences 57B (2) (2002) S69-S78.

[24] G.R. Hall, K.C. Buckwalter, Progressively lowered stress threshold: A conceptual model for care of adults with Alzheimer's disease, Archives of Psychiatric Nursing 1 (6) (1987) 399-406.

[25] D. Brooker, C. Surr, Dementia Care Mapping: Principles and Practice, University of Bradford, UK, 2005.

[26] J.M. Cioffi, A. Fleming, L. Wilkes, M. Sinfield, J.
LeMiere, The effect of environmental change on residents with dementia, Dementia 6 (2) (2007) 215-231.

[27] K. Day, M.P. Calkins, Design and dementia, in: R. Bechtel (Ed.), Handbook for Environmental Psychology, John Wiley \& Sons, USA, 2002, pp. 374-393.

[28] C.R. Kovach, A.M. Schlidt, The agitation-activity interface of people with dementia in long-term care, American Journal of Alzheimer's Disease and Other Dementia 6 (4) (2001) 240-246.

[29] S.Y. Lee, A. Morelli, Multi-sensory environment and agitated behavior in ageing residents with dementia, Journal of Architectural Research 12 (1) (2010) 1-8. 